\title{
Ocorrência de aglưtininas antileptospiras em suínos de criação intensiva no estado do Rio de Janeiro - RJ
}

\section{Occurrence of leptospira antibodies in pigs from Rio de Janeiro, Brazil}

\author{
Antonio Carlos Faria Ramos, ${ }^{\star}$ Suzana Fráguas, ${ }^{\star \star}$ Paula Ristow, ${ }^{\star \star \star}$ Renato Varges, ${ }^{\star \star \star \star}$ Verônica Cardoso, ${ }^{* \star \star \star}$ \\ Diogo Fernandes Braga, ${ }^{\star \star \star \star \star}$ Walter Lilenbaum ${ }^{\star \star \star \star \star \star}$
}

\section{Resumo}

Foram examinadas 351 amostras de soros sangüíneos de matrizes de suínos oriundos de 18 propriedades de exploração intensiva localizadas em dez municípios do estado do Rio de Janeiro. O teste sorológico foi realizado pela técnica de soroaglutinação microscópica (MAT) utilizando-se antígenos vivos dos serovares pomona, wolffi, bratislava, hardjo, tarassovi, copenhageni, icterohaemorrhagiae e bataviae. Foram observadas $232(66,09 \%)$ reações positivas. Das 18 propriedades examinadas, $16(88,89 \%)$ apresentaram índices de reatividade. O serovar icterohaemorrhagiae apresentou o maior percentual de observações com $28,48 \%$ de ocorrências, seguido de pomona com $11,97 \%$, copenhageni $9,69 \%$, tarassovi com $6,55 \%$, hardjo com 4,56\%, bratislava com 2,56\% e wolffi, com 2,28\%. Reações para o serovar bataviae não foram evidenciadas em nenhuma propriedade pesquisada. As provas sorológicas demonstram a alta ocorrência de sororreatividade para leptospiras nas propriedades, com alteração na freqüência de serovares anteriormente descritos como os prevalentes na suinocultura.

Palavras-chave. leptospirose, suínos, reprodução.

\begin{abstract}
Blood samples from 351 sows originated from 18 herds of Rio de Janeiro, Brazil were examined by the microscopic agglutination test (MAT) using serovars pomona, wolffi, bratislava, hardjo, tarassovi, copenhageni, icterohaemorrhagiae and bataviae as antigens. Two hundred thirty two $(66.09 \%)$ reactions were observed, in $16(88.89 \%)$ of the examined herds. Serovar icterohaemorrhagiae was the most frequently observed $(28.48 \%)$, followed by pomona (11.97\%), copenhageni $(9,69 \%)$, tarassovi $(6.55 \%)$, hardjo $(4.56 \%)$, bratislava $(2.56 \%)$ and wolffi $(2.28 \%)$. Reactions for serotype bataviae were not evidenced. The serologic tests demonstrate the high occurrence of agglutinins anti leptospiras in the herds with alteration in the frequency of involved serovars. A permanent surveillance of the herds and detection of outbreaks of leptospirosis of swine from Rio de Janeiro, Brazil was suggested.
\end{abstract}

Keywords. leptospirosis, pigs, reptoduction.

\section{Introdução}

A leptospirose é uma doença comum nos suínos ao redor do mundo. Nesta espécie, os animais infectados, mesmo que aparentemente sadios, podem eliminar leptospiras pela urina, sendo, portanto, considerados uma grande fonte de infecção para outros hospedeiros e até mesmo para o homem. A leptospirose nesta espécie freqüentemente determina sintomas ligados à esfera da reprodução, tais como abortamentos, ocorrência de natimortos e prematuros e baixa da eficiência reprodutiva do plantel.
Os suínos podem ser infectados pelos serovares icterohaemorrhagiae ou canicola, que determinam sintomatologia aguda. Nas infecções determinadas por estas amostras, os fatores epidemiológicos e clínicos diferem nos serovares bratislava, tarassovi e pomona, já que estes são considerados adaptados ao hospedeiro (Faine et al., 2000).

O envolvimento de leptospiras com a eficiência reprodutiva dos animais foi discutido por Kirkbride e Mc Adargh (1978). Ao analisarem retrospectivamente seis anos de pesquisa diagnóstica

* MVD, MSc. Autônomo.

* Médica-veterinária

*** Médica-veterinária; Mestranda em Microbiologia (UFRJ)

**** Acadêmicos de Medicina Veterinária, Bolsistas PIBIC/CNPq/UFF

${ }_{\star \star \star \star \star *}$ MSc, PhD Departamento de Zootecnia, Universidade Federal Fluminense

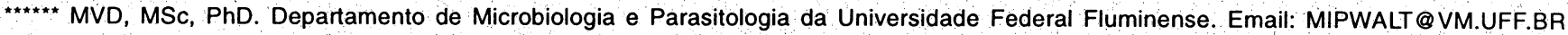


no Centro-Oeste dos EUA, observaram que $16,5 \%$ dos casos de abortamento envolvidos eram de origem bacteriana e que a leptospirose respondia por $9,8 \%$ das infecções.

No Brasil, o trabalho pioneiro no isolamento de leptospiras em suínos foi realizado por Guida em 1947/48, que ao examinar 50 rins de suínos provenientes de localidades do interior do estado de São Paulo, isolou três amostras de Leptospira. Santa Rosa et al., em 1962 realizaram uma investigação em criatórios de suínos com problemas reprodutivos do estado de São Paulo, principalmente abortamentos, e relataram $80 \%$ de reatividade, com predomínio dos serovares pomona $(47,3 \%)$, icterohaemorrhagiae $(22,4 \%)$ e canicola $(7,3 \%)$. No Instituto Biológico de São Paulo, Santa Rosa et al. (1969/70) avaliaram retrospectivamente os trabalhos com aglutininas antileptospiras, num total de 3.242 amostras de soros de suínos e encontraram $19,5 \%$ de reatividade, com prevalência de pomona.

No estado do Rio de Janeiro um inquérito sorológico de leptospirose realizado por Ramos et al. (1981) revelou 4,83\% de animais reativos, distribuídos entre os serovares tarassovi $(3,25 \%)$, pomona $(1,1 \%)$, autumnalis, canicola, pyrogenes, castelloni e javanica $(0,09 \%$ cada) em 1.045 soros. No Chile, Riedemann \& Zamora (1990) verificaram após uma escolha randômica em suínos abatidos aparentemente saudáveis, $16,0 \%$ de reatividade, sendo o serovar icterohaemorrhagiae o mais freqüente com $13,0 \%$. Ao analisarem 521 soros suínos provenientes do Norte da Espanha, Perea et al. (1994) observaram que $10,56 \%$ dos suínos testados apresentaram reações para leptospiras, prevalecendo o serovar pomona $6,53 \%$, seguido de castellonis $(1,15 \%)$ e sejroe com $1,15 \%$.

Desta forma, dada sua importância e impacto econômico como doença da esfera da reprodução, além da carência de informações atuais sobre leptospirose em suínos do estado do Rio de Janeiro, este estudo teve por objetivos identificar a freqüência de sororreatividade em suínos mantidos em criações tecnificadas de diferentes regiões e tamant do do Rio de Janeiro, bem como os principais serovares envolvidos.

\section{Material e métodos}

Propriedades - Foram visitadas 18 propriedades de exploração intensiva de ciclo completo e tecnificadas, i.e., que utilizam normas e padrões sanitários e zootécnicos compativeis com a moderna produção suinícola, localizadas em municípios que historicamente produzem suínos no estado do Rio de Janeiro. As propriedades eram classificadas quanto ao seu tamanho em: pequenas criações $(P)$ onde o número de matrizes era inferior a 100 fêmeas, criações entre 101 e 200 matrizes como médias (M) e unidades onde o número de fêmeas era superior a 201 matrizes como grandes $(\mathbf{G})$ e sua localização geográfica, em Região Serrana, Metropolitana e Sul. Todas as propriedades apresentavam histórico de desordens reprodutivas, como alto número de repetições de cio, abortamentos esporádicos e baixo número de leitões ao nascer, sendo que em três destas os problemas persistiam até o momento da coleta.

Amostras - Foram examinadas 351 amostras de soros sangüíneos de matrizes de suínos provenientes dos criatórios selecionados. Os animais não eram testados regularmente para leptospirose. O sangue para a obtenção do soro foi coIhido diretamente dos ramos venosos auriculares, identificado e transportado sob refrigeração ao laboratório, centrifugado e mantidos a $(-) 20^{\circ} \mathrm{C}$ até a realização dos testes sorológicos.

Testes - O teste sorológico foi realizado pela técnica de soroaglutinação microscópica em tubos (MAT) com antígenos vivos e leitura em microscopia em campo escuro conforme descrito por Myers (1985) e de acordo com a recomendação técnica da Organização Mundial de Saúde (OIE, 1996). Como antígenos foram utilizadas amostras jovens de leptospiras mantidas em meio Ellinghausen dos serovares bataviae (Van Tienen), bratislava (Jez bratislava), copenhageni (M 20), hardjo (Hardjoprajitno), icterohaemorrhagiae (RGA), pomona (Pomona), tarassovi (Perepelicin) e wolffi (3705).

Análise estatística - O número de propriedades a ser visitado e de amostras colhidas a fim de representarem os criatórios tecnificados do estado do Rio de Janeiro foram calculadas de acordo com a fórmula para cálculo amostral Modelo I (Nota técnica $\mathrm{n}^{\circ} 18$ do Centro Panamericano de Zoonoses), a partir de dados fornecidos pela EMATER - RJ (2000). A significância das diferenças entre as freqüências foi avaliada pelo teste não-paramétrico do qui-quadrado $\left(x^{2}\right)$.

\section{Resultados}

Das 351 amostras de soros testadas, 232 (66,09\%) demonstraram reações positivas. Das 18 propriedades examinadas, $16(88,89 \%)$ apresentaram índices de reatividade, compreendidos entre $15,0 \%$ (município de Cordeiro) e $84,0 \%$ (município de Nova Friburgo), com índice médio de reatividade entre as criações de $40,17 \%$.

Quanto à distribuição por propriedades, observou-se uma predominância do serovar icterohaemorrhagiae, encontrado em todas as criações que apresentaram alguma reatividade. Já pomona esteve presente em 12 granjas $(66,66 \%)$, configurando sua ampla distribuição pelas suinoculturas do estado do Rio de Janeiro. Outros serovares verificados foram copenhageni em nove criações $(50,0 \%)$, tarassovi em seis $(33,33 \%)$, bratislava em cinco $(27,77 \%)$ e wolffi em três $(16,66 \%)$.

No cômputo geral de amostras testadas, o serovar icterohaemorrhagiae obteve o maior percentual de reações com $28,48 \%$ de ocorrências com 100 averiguações e títulos de até 3.200 , seguido de pomona com $11,97 \%$ ou 42 observações com titulação até 400 , copenhageni $9,69 \%$ com títulos de até 1600 , tarassovi, 23 observações $(6,55 \%)$ com títulos que não excederam a 200 , hardjo, com $4,56 \%$ com títulos até 400 , bratislava $(2,56 \%)$ e reações até 200 e wolffi, com $2,28 \%$, com titulação até 800 (Tabela 1). Não se evidenciaram reações para o serovar bataviae em nenhuma propriedade pesquisada.

No que diz respeito à distribuição geográfica das propriedades observou-se que a região Serrana foi a que apresentou 0 maior número de amostras testadas, por centralizar a maior parte das criações do estado do Rio de Janeiro. Nesta região, houve 152 amostras reativas sobre um total de 184 animais testados. Este percentual, de $82,6 \%$ de reatividade, é significativamente superior $(p<0,05)$ ao verificado para as regiōes Metropolitana, com 60,0\% e Sul, que apresentou $36,8 \%$ das amostras reativas (Tabela 2). 
Tabela 1: Freqüência de aglutininas antileptospiras em soros de suínos do estado do Rio de Janeiro - 2001

\begin{tabular}{l|c|c|c}
\hline Sorotipo & $\begin{array}{c}\text { Amostras } \\
\text { Reativas }\end{array}$ & $\begin{array}{c}\% \\
\text { Reativos }\end{array}$ & $\%$ Total \\
\hline icterohaemorrhagiae & 100 & 43,11 & 28,48 \\
pomona & 42 & 18,11 & 11,97 \\
\hline copenhageni & 34 & 14,65 & 9,69 \\
\hline tarassovi & 23 & 9,91 & 6,55 \\
\hline hardjo & 16 & 6,89 & 4,56 \\
\hline bratislava & 9 & 3,88 & 2,56 \\
\hline wolffi & 8 & 3,45 & 2,28 \\
\hline TOTAL & 232 & 100 & 66,09 \\
\hline
\end{tabular}

Quanto à distribuição dos serovares pelas regiões geográficas, verificou-se que icterohaemorrhagiae predominou em todas as regiões testadas, com indices de $20,96 \%$ a $34,78 \%$ de ocorrência. No entanto, a ocorrência dos outros serovares variou de acordo com a região estudada. Enquanto pomona e copenhageni se mostraram igualmente freqüentes na região Serrana, o que se verificou na região Sul e Metropolitana foi que a ocorrência de pomona se mostrou bastante superior à de copenhageni (Tabela 2).

Tabela 2: Freqüência de aglutininas antileptospiras em amostras de soros suínos de acordo com a região geográfica do estado do Rio de Janeiro 2001

\begin{tabular}{l|c|c|c|c|c|c}
\hline \multirow{2}{*}{ SOROTIPOS } & \multicolumn{2}{|c|}{ SERRANA } & \multicolumn{2}{c|}{ METROPOLITANA } & \multicolumn{2}{c}{ SUL } \\
\cline { 2 - 7 } & Reativos & $\%$ & Reativos & $\%$ & Reativos & $\%$ \\
\hline icterohaemorrhagiae & 64 & 34,8 & 18 & 22,6 & 18 & 20,9 \\
\hline pomona & 25 & 13,6 & 11 & 13,8 & 6 & 6,7 \\
\hline tarassovi & 14 & 7,6 & 6 & 7,5 & 3 & 3,4 \\
\hline copenhageni & 25 & 13,6 & 8 & 10 & 1 & 1,2 \\
\hline bratislava & 7 & 3,8 & 1 & 1,2 & 1 & 1,2 \\
\hline hardjo & 10 & 5,4 & 3 & 3,7 & 3 & 3,4 \\
\hline wolffi & 7 & 3,8 & 1 & 1,2 & - & - \\
\hline TOTAL & 152 & $\mathbf{8 2 , 6 ^ { \mathrm { a } }}$ & $\mathbf{4 8}$ & $\mathbf{6 0 , 0}$ & $\mathbf{3 2}$ & $\mathbf{3 6 , 8}$ \\
\hline
\end{tabular}

$p<0,05$

No que diz respeito à distribuição das propriedades pelo tamanho, observou-se que a ocorrência de animais sororeativos foi significativamente maior $(p<0,05)$ nas propriedades de tamanho grande, embora não se tenha verificado diferenças significativas entre as propriedades médias e pequenas. No que diz respeito à distribuiçãa dos serovares por tamanho de propriedade verificou-se que icterohaemorrhagiae predominou em todas as regiões testadas, com índices de $20,5 \%$ a $38,4 \%$ de ocorrência. O serovar pomona se mostrou significativamente mais freqüente $(p<0,05)$ nas propriedades pequenas em relação às médias e grandes criações. No entanto, sua freqüência não diferiu significantemente $(p>0,05)$ entre as médias e grandes propriedades (Tabela 3).

\section{Discussão e conclusões}

$O$ índice total de reatividade verificado no presente estudo é bastante superior aos descritos em inquéritos epidemiológicos amplos realino. Janeiro - 2001

$p<0,05$ zados na Tailândia (Suwanchareon et al., 1997), EUA (Kirkbride e McAdaragh, 1978), Espanha (Perea et al., 1994), Venezuela (Mazzonelli et al., 1979), Chile (Riedemann e Zamora, 1990) e, no Brasil, em São Paulo (Santa Rosa et al., 1970; Favero et al., 2002) e Minas Gerais (Faria et al., 1989), onde se observaram índices variando de $7,7 \%$ a $17,4 \%$.

Ao ser comparado, no entanto, com pesquisadores que investigaram surtos de abortamento ou propriedades com problemas reprodutivos, verifica-se uma maior concordância de resultados. Oliveira et al. (1987) identificaram $42,6 \%$ de reatividade em suínos reprodutores com abortamentos no Rio Grande do Sul; Gírio et al. (1998) relataram $70,88 \%$ de positividade em fêmeas suínas descartadas por apresentarem insuficiência reprodutiva no Estado de São Paulo e Delben (2000) que encontraram $43,27 \%$ de sororreatividade em 508 amostras de soro suíno com e sem histórico de problemas reprodutivos do estado do Paraná. Ao analisarem fêmeas de suínos descartadas pör baixa performance reprodutiva, Delben et al. (2002) verificaram soropositividade de $66,66 \%$, configurando a leptospirose como uma das principais enfermidades que levam à eliminação de matrizes do plantel suí-

Em um inquérito sorológico para leptospirose em suínos no estado do Rio de Janeiro e região limítrofe, Ramos et al. (1981) obtiveram $4,97 \%$ de sororreatividade, o que difere muito dos resultados obtidos no presente estudo. Esta diferença poderia ser explicada pela préseleção realizada no presente trabalho, em que se testaram animais oriundos de plantéis com histórico de problemas reprodutivos.

No presente estudo se observou forte predominância de icterohaemorrhagiae, seguido de pomona e menor importância de serovares de origem bovina ou silvestre, como hardjo ou bataviae. Estes achados concordam com Faine et al. (2000), que correlacionam o crescimento da moderna suinocultura e o sistema de total confinamento adotado em criações tecnificadas ao decréscimo na incidência de leptospirose adquiridas de animais selvagens e bovinos; porém, segundo os autores, infecções com os serovares bratislava, pomona e tarassovi, além de infecções incidentais por icterohaemormagiae continuariam a acarretar grandes problemas.

Tabela 3: Freqüência de aglutininas antileptospiras em amostras de soros suínos de acordo com o tamanho das propriedades do estado do Rio de

\begin{tabular}{l|c|c|c|c|c|c}
\hline \multirow{2}{*}{ SOROTIPO } & \multicolumn{2}{|c|}{ PEQUENA } & \multicolumn{2}{c|}{ MÉDIA } & \multicolumn{2}{c}{ GRANDE } \\
\cline { 2 - 7 } & Reativos & $\%$ & Reativos & $\%$ & Reativos & $\%$ \\
\hline icterohaemorrhagiae & 18 & 20,5 & 27 & 22,5 & 55 & 38,4 \\
\hline Pomona & 18 & $20,5^{\mathrm{a}}$ & 12 & 10 & 12 & 8,4 \\
\hline Tarassovi & 8 & 9,1 & 7 & 5,8 & 8 & 5,6 \\
\hline copenhageni & 1 & 1,1 & 14 & 11,7 & 19 & 13,3 \\
\hline Bratislava & 1 & 1,1 & 1 & 0,8 & 7 & 4,9 \\
\hline Hardjo & 1 & 1,1 & 5 & 4,2 & 10 & 7 \\
\hline Wolffi & 1 & 1,1 & 3 & 2,5 & 4 & 2,8 \\
\hline TOTAL & 48 & 54,5 & $\mathbf{6 9}$ & $\mathbf{5 7 , 5}$ & 115 & $\mathbf{8 0 , 4 ^ { \mathrm { a } }}$ \\
\hline
\end{tabular}


O sorogrupo Icterohaemorrhagiae apresentou $38,17 \%$ das amostras testadas, representadas pela soma das reações observadas para os serovares icterohaemorrhagiae $(28,48 \%)$ e copenhageni $(9,69 \%)$, conforme Gráfico 1. Este achado está em concordância com os relatados por Van Til e Dohoo (1991), que relataram $57,8 \%$, Girio et al. (1998), com $60,08 \%$ e Fávero et al. (2002) com 33,3\% de reações para este sorogrupo. Este sorogrupo apresenta como reservatórios os roedores sinantrópicos, em especial o. Rattus novergicus (Lilenbaum et al. 1993) e está relacionado com vários prejuízos econômicos na suinocultura em função das alterações reprodutivas (Faine et al., 2000). A forte presença deste sorogrupo nas criações indica uma forte ocorrência de infecções incidentais e a necessidade premente de serem estabelecidos programas de controle de roedores nas suinoculturas do estado do Rio de Janeiro, o que está de acordo com os relatos de Oliveira (1994).

O serovar pomona foi verificado em $11,97 \%$ das amostras testadas e configurou-se como o segundo mais freqüente nas criações tecnificadas do Estado do Rio de Janeiro. Títulos mais baixos, como os verificados para este serovar, que não ultrapassaram 400 , estão freqüentemente relacionados com o estado de portador ou à infecção crônica, embora passiveis de determinar transtornos reprodutivos e perdas econômicas às criações. Estes valores são bastante inferiores aos relatados por Santa Rosa et al. (1962), de $47,27 \%$, Larsson et al. (1984), com 35,1\% e Oliveira et al. (1987), com $62,45 \%$. Este serovar tem como reservatório principal os suínos, sem necessidade de outras espécies envolvidas em seu ciclo epidemiológico. Era o mais freqüentemente relatado nos primeiros estudos sobre leptospirose suína no Brasil e no mundo. No entanto, a tecnificação das criações suínas, associada ao incremento das medidas profiláticas desta infecção reduziu seu impacto como agente de enfermidade da esfera da reprodução de suínos.

Fêmeas infectadas pelo serovar bratislava próximas do momento da cobertura ou durante os primeiros dias de gestação demonstram como resultados características subótimas de fertilidade, decréscimo da taxa de leitões nascidos e repetições de cio com atraso do retorno do estro sugerindo morte embrionária. Esta conseqüência é devida a colonização do trato reprodutivo por este serovar (Faine et al., 2000). Oliveira (1994) e Girio et al. (1998) relataram evidências de infecção por este serovar em granjas com problemas de reprodução no Rio Grande do Sul e no presente estudo, foi identificada sororreatividade a este serovar em nove soros, ou $2,56 \%$ das amostras testadas. Este achado é de grande importância, já que este não era relatado com freqüência em estudos anteriores e vem sendo responsabilizado por alterações como retornos ao cio, descargas vulvares e abortamentos em fase final de gestação (Faine et al., 2000). Esta amostra é de difícil isolamento e apresenta capacidade de multiplicar-se e persistir no trato genital de machos e fêmeas de suínos tornando a via sexual também importante para sua transmissão (Bolin e Cassels, 1990):

A concentração de casos reativos na região Serrana não foi um achado inesperado. Michna (1970) indica que a incidência e prevalência dos serovares diferem consideravelmente entre os países e entre seus distritos/estados. Já Mazzonelli et al. (1979) descreveram importante diferença na ocorrência de sororreatividade para leptospirose entre diferentes regiões na Venezuela, e Faria et al. (1989) relataram significativa diferença de freqüência de sororreatividade entre municípios no estado de Minas Gerais.

O tamanho das propriedades também influiu na freqüência e distribuição de serovares observados. Constatou-se uma ocorrência significativamente maior de sororreatividade nas grandes criações em relação às médias e pequenas propriedades $(p<0,05)$. No que se refere à freqüência do serovar bratislava, este se mostrou bem mais presente nas propriedades grandes $(4,9 \%)$ do que nas médias $(0,8 \%)$ e pequenas criações $(1,1 \%)$. Infelizmente, o reduzido número de amostras reativas para este serovar não permite uma análise estatística a fim de confirmar a significância deste achado. Já a reatividade para pomona é significativamente maior $(p<0,05)$ em propriedades pequenas $(20,5 \%)$ do que nas médias $(10,0 \%)$ e grandes $(8,4 \%)$, conforme Tabela 3 .

Assim, pode-se concluir que é alta a ocorrência de sororreatividade para leptospiras em propriedades de criação suína intensiva e com histórico de distúrbios reprodutivos no Estado do Rio de Janeiro, com uma significativa concentração de casos reativos na região Serrana. Uma importante alteração na freqüência de serovares envolvidos especialmente no que diz respeito ao incremento da ocorrência de icterohaemorrhagiae e redução de pomona foi observado. A emergência de bratislava é um achado de importância que requer maiores estudos.

\section{Agradecimentos}

Ao professor Dr. S. A. Vasconcellos, do Laboratório de Medicina Veterinária Preventiva e Saúde Animal/USP, e CNPq e FAPERJ pelo auxílio financeiro para a realização deste trabalho.

\section{Referências}

BOLIN, C. A. e CASSELLS, J. A. Isolation of Leptospira interrogans serovar bratislava from stillborn and weak pigs in lowa. Journal of American Veterinary Medical Association, v.196, n.10, p.1601-1604, 1990.

DELBEN, A.C.D. Leptospirose suína. Londrina 200032 p. Dissertação (Mestrado) Faculdade de Medicina Veterinária, Departamento de Medicina Veterinária Preventiva, Universidade Estadual de Londrina.
DELBEN, A.C.D.; FREITAS, J.C.; BRACARENSE, A.P.F.R.L.; MULLER, E.E.; OLVIERA, R.C. Leptospirose em matrizes suínas de abatedouro: investigação sorológica e histopatológica. Revista Brasileira de Microbiologia, 2002. no prelo.

FAINE, S.; ADLER, B.; BOLIN, C.; PEROLAT, P. Leptospira and Leptospirosis. $2^{\text {nd }}$ ed., Melbourne, Austrália: MedSci, 2000.

FARIA, J. E.; RIBEIRO, M. F.B.;SANTOS, J.L.; DALE, R. Freqüência de aglutininas antileptospiras em soros sanguíneos de suínos das microrregiões de Viçosa e Ponte Nova - MG. Arquivo Brasileiro de Medicina Veterinária e Zootecnia, v. 41, n. 5, p. 381-388, 1989. 
FÁVERO, A.C.M.; PINHEIRO, S.R.; VASCONCELLOS, S.A., MORAIS, Z.M.; FERREIRA, F.; FERREIRA NETO, J.S. Serovares de Leptospiras prevalentes em exames sorológicos de bubalinos, bovinos, caprinos, eqüinos, suínos e cães de diversos estados brasileiros. Ciência $R u$ ral, v. 32, n. 4, 2002. no prelo.

GIRIO, R.J.S., DIAS, H.L.T., MATHIAS, L.A., SANTANA, A.E., ALESSI, A.C. Alterações reprodutivas, hematológicas e anatomopatológicas em fêmeas suínas com títulos de anticorpos contra Leptospira interrogans sorotipo icterohaemorrhagiae. Revista brasileira de $\mathrm{Ci}$ ência Veterinária, v. 5, n. 3, p. 99-103,1998.

GUIDA, V.O. Sobre a presença de Leptospira em suínos no Brasil. Arquivos do Instituto Biológico, São Paulo, v. 18, p. 285-287, 1947 1948.

KIRKBRIDE, C. A.; McADARGH, J. P. Infectious agents associated with fetal and early neonatal death and abortion in swine. Journal American Veterinary Medical Association, v. 172, n. 4, p. 480-483, 1978.

LARSSON, C.E., YASUDA, P.H., ROSA, C.A.S., COSTA, N.O. Leptospirose suína. Inquérito sorológico e bacteriológico em municípios dos estado de São Paulo, do Paraná e de Santa Catarina. Revista da Faculdade de Medicina Veterinária e Zootecnia da Universidade de São Paulo, v. 21, n. 1, p. 43-50, 1984.

LILENBAUM,W.; RIBEIRO,V.; MARTIN,E.; BISPO,V. Estudo sorológico para detecção de anticorpos antileptospira em Rattus norvegicus de Duque de Caxias, Rio de Janeiro, Brasil. Revista Latinoamericana de Microbiologia, v. 35, n. 4, p. 357-360, 1993.

MAZZONELLI, J.; JELAMBI, F.; ALVAREZ, E.; CANAL, H.; NAVA, B. O. Estúdio prospectivo de la leptospirosis porcina en granjas organizadas de Venezuela. Boletin de La Oficina Sanitária Panamericana, v. 87, n. 1, p. 60-71, 1979.

MICHNA, S. W. Leptospirosis. The Veterinary Record, v. 86, p. 484 496, 1970.

MYERS, D.M. Manual de métodos para el diagnóstico de Leptospira. Série Buenos Aires; Centro Panamericano de Zoonosis, 1985 (Nota Técnica 30)

OFFICE INTERNATIONAL DES EPIZOOTIES. In: Manual of Standards. 1996 Disponível em: <http:// www.oie.int/eng/norms/mmanual/ A_00008.html> Acesso em junho 2001.
OLIVEIRA, S.J. Atualização nos conceitos sobre leptospirose em suínos. A Hora Veterinária, n. 79, p. 52-55, maio/jun., 1994.

OLIVEIRA, S.J., GUIZZARDI, I.I., VIDOR, T., OLIVEIRA, L.G., BRUCHMANN, H.E.A., MARTINS, R.M.; ROEHE, P.M., BANGEL, E.V. Testes sorológicos para diagnóstico de Leptospirose, Peste Suína Africana e Doença de Aujeszkuy em granjas de reprodutores suínos no Rio Grande do Sul (Ano 1984), Arquivo Brasileiro de Medicina Veterinária e Zootecnia, v. 39, n. 3, p. 451-460, 1987.

PEREA, A.; GARCIA, R.; MALDONADO, A.; TARRADAS, M. C.; LUQUE, I.; ASTORGA, R.; ARENAS, A. Prevalence of antibodies to different Leptospira interrogans serovars in pigs on large farms. Journal of Veterinary Medicine, v. 41, n. 7-8, p. 512-516, 1994.

RAMOS, A.A., CORDEIRO, F., GUIDA, H.G., ANDRADE, V.L.B. Inquérito sorológico de leptospirose em suínos no estado do Rio de Janeiro e região limítrofe. Pesquisa Veterinária Brasileira, v. 1, n. 3, p. 81-83, 1981.

RIEDEMANN, G. S.; ZAMORA, B.J. Evidencia serologica de infección por leptospiras em porcinos clinicamente sanos de la $X$ Region, Chile. Avances em Ciências Veterinárias, v. 5, n. 2, p. 139-141, 1990.

SANTA ROSA, C.A.; PESTANA DE CASTRO, A.F.; TROISE, C. Isolamento de Leptospira pomona de suíno em São Paulo. Arquivos do Instituto Biológico, São Paulo, v. 29, p. 165-174, 1962.

SANTAROSA, C.A.; PESTANA DECASTRO, A.F.; SILVA, A.S.; TERUYA, J.M. Nove anos de leptospirose no Instituto Biológico de São Paulo. Revista do Instituto Adolfo Lutz, v. 29/30, p. 19-27, $1969 / 70$.

SANTA ROSA, C.A.; GIORGI, W.; SILVA, A.S.; TERUYA, J.M. Aborto em suíno: isolamento conjunto de Leptospira, sorotipo icterohaemorrhagiae e Brucella suis. Arquivo do Instituto Biológico, São Paulo, v. 37, n. 1, p. 9-13, 1970.

SUWANCHAREON, D.; INTARASRI, N.; SIRIWAN, C. Detection of Leptospira antibodies in swine serum samples from farms with a history of abortion in Nakhon Pathom, Chachoengsao and Saraburi provinces of Thailand. Journal of the Thai Veterinary Medical Association, v. 48, n. 2, p. 17-22, 1997.

VAN TIL, L.; DOHOO, I. R. A serological survey of leptospirosis in Prince Edward Island swine herds and its association with infertility. Canadian Journal Veterinary Research, v. 55, p. 352-355, 1991. 